\title{
SOME RADIOCARBON DATES FOR TUFAS OF THE CRAVEN DISTRICT OF YORKSHIRE
}

\author{
ALLAN PENTECOST ${ }^{1}$, P M THORPE ${ }^{2}$, D D HARKNESS ${ }^{3}$ and T C LORD ${ }^{4}$
}

ABSTRACT. ${ }^{14} \mathrm{C}$ dates of relict tufa deposits at Gordale indicated a Subboreal age when the carbonate age was corrected with empirical bedrock dilution factors ' $q$ ' of 0.79 or 0.85 . Estimates of 'apparent age,' based on extrapolated $\delta^{13} \mathrm{C}$ values were about twice those obtained with $\mathrm{q}$, and the $1 \sigma$ error was large. The $\delta^{13} \mathrm{C}$ values of tufa samples were not correlated with carbonate age and were close to $-10 \%$. Application of $q$ values in this district requires caution as they appear to be site-specific. We recommend that wherever possible, levels of ${ }^{13} \mathrm{C}$ and ${ }^{14} \mathrm{C}$ are measured in the associated tufa-depositing water, and an empirical dilution factor employed.

\section{INTRODUCTION}

In this paper we report on some ${ }^{14} \mathrm{C}$ dates of tufas and associated organic material from the Craven district of Yorkshire. This region contains the widest range of tufas in the UK and tufa is still forming at many sites (Pentecost 1981; Pentecost \& Lord 1988). Particular attention has been paid to Gordale Beck with its large cascade tufas. Carbon isotope studies of the stream waters, and some of the tufas, have been previously reported by Thorpe (1981) and Thorpe et al (1981). We have obtained further data from Gordale and report on some additional sites. At two of these, organic carbon was associated with the deposits.

\section{METHODS}

Tufa samples weighing ca $100 \mathrm{~g}$ were collected from discrete areas at each site. Pretreatment of the raw sample materials to recover specific carbonaceous components and the subsequent determination of isotope enrichment values were carried out at the NERC radiocarbon laboratory.

Carbonates were hydrolyzed with $5 \mathrm{M}$ hydrochloric acid. Organic residues, acid-washed charcoals and the collagen fraction extracted from bones were oxidized by quantitative high-pressure combustion. In all instances, the product carbon dioxide was dried and collected by cryogenic trapping and then cleaned by vacuum distillation. Radiocarbon measurement was by liquid scintillation counting of benzene synthesized from the primary carbon dioxide produced (Harkness \& Wilson 1973). Conventional age values were calculated at the $\pm 1 \sigma$ level for overall analytical confidence, in compliance with their definition by Stuiver \& Polach (1977). The associated $\delta^{13} \mathrm{C}(\mathrm{PDB})$ values were recorded for carbon dioxide produced by quantitative burn-back of a small $(5 \mu \mathrm{l})$ aliquot of the benzene synthesized for radiometric counting. It is important to note, therefore, that the ${ }^{13} \mathrm{C}$ enrichment data in Table 1 may reflect a degree of isotopic fractionation induced during benzene synthesis.

\section{RESULTS AND DISCUSSION}

\section{Gordale}

Gordale contains some of the largest cascade tufas in the UK, and has been well studied (Thorpe, Otlet \& Sweeting 1980; Thorpe et al 1981; Thorpe 1981; Pentecost 1981; Pentecost \& Lord 1988). The stream rises in marshland and tufas are deposited over a $4 \mathrm{~km}$ length beginning $1 \mathrm{~km}$ downstream. In the upper gorge, a series of tufa terraces up to $4 \mathrm{~m}$ thick have been partly cut through by the stream and form a prominent bench, $1 \mathrm{~km}$ long (Fig 1). Sections of tufa were exposed for dating on both sides of the stream (National Grid Refs 34/91366444 and 34/91336449 for east and west banks, respectively) and samples taken for dating near the top and bottom of the profiles (Fig 1). The material consisted of a pale, soft crumb-like tufa. Narrow iron-rich layers-perhaps representing former piezomet-

\footnotetext{
1 Division of Biosphere Sciences, King's College London, Campden Hill Road, London W8 7AH, England Australia

Geological Survey of Western Australia, Department of Mines, 66 Adelaide Terrace, Perth 6000, Western

${ }^{3}$ Scottish Universities Research and Reactor Centre, East Kilbride, Glasgow, Scotland

4 Kern Knotts, Stainforth, Settle, North Yorkshire, England
} 


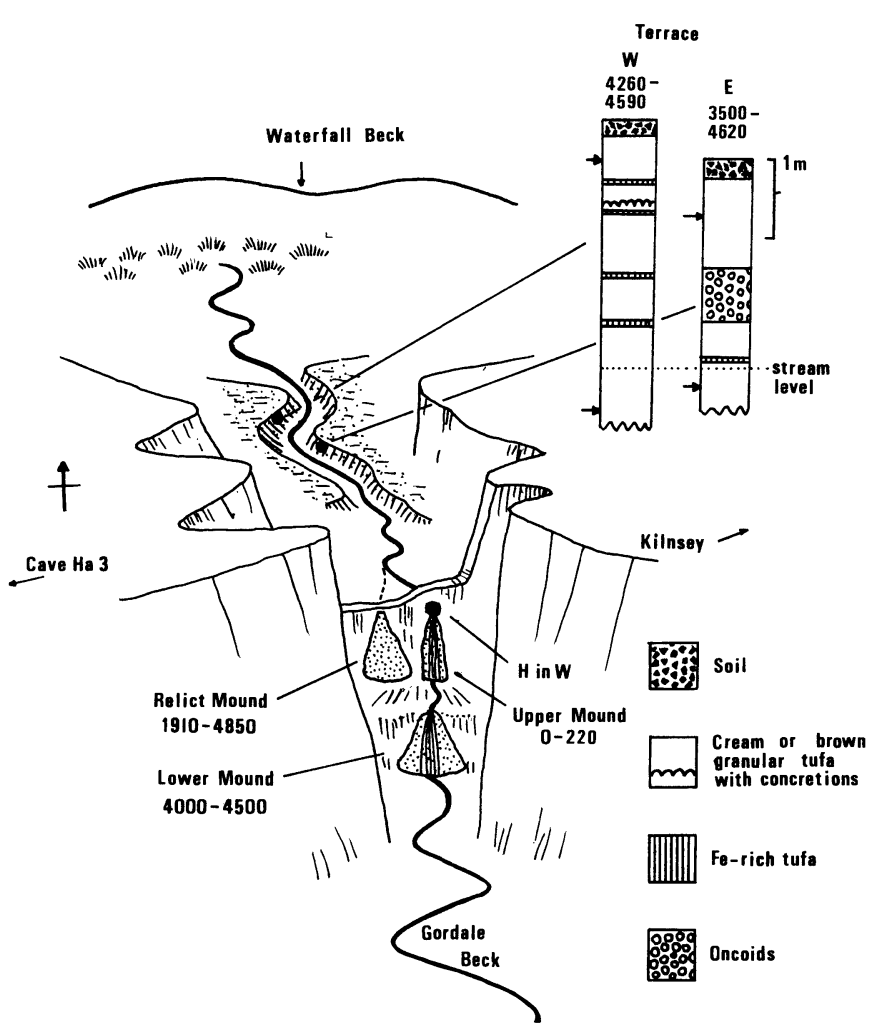

Fig 1. Diagram of Gordale Beck, looking north. Tufa terraces occur in the upper gorge and extend for ca $800 \mathrm{~m}$ downstream. In lower Gordale there are three cascade tufas, two of which (relict upper mound, lower mound) are inactive. Arrows show location of samples collected near the top and bottom of the profiles.

ric surfaces, and beds of oncoids also occurred. There was insufficient organic matter for dating.

The carbonate dates were corrected for bedrock dilution using a factor ' $q$ ' (Vogel 1970). A value of $q=0.85$ is commonly employed for tufa and appears to have general applicability (Geyh 1973; Srdoc et al 1980; Srdoc, Horvatincic \& Obelic 1983) but a detailed study of the Gordale waters by Thorpe (1981) gave a value of $0.82 \pm 0.022 \sigma$ at the cascades.

Measurements of ${ }^{14} \mathrm{C}$ levels in the Gordale Beck springs and at the cascades demonstrated downstream enrichment of ${ }^{14} \mathrm{C}$ amounting to $3.4 \mathrm{pMC}$ caused by atmospheric $\mathrm{CO}_{2}$ exchange, and we estimate for the terraces, which lie above the cascades (Fig 1), a $q$ value of $0.79 \pm 0.03 \sigma$. Corrected dates using $q$ values of 0.79 and 0.85 are given in Table 1 . The corresponding $1 \sigma$ errors for these corrected dates are $\pm 290 \mathrm{yr}$ for $\mathrm{q}=0.85$ and $\pm 310 \mathrm{yr}$ for $\mathrm{q}=0.79$. Although the sections were separated laterally by $100 \mathrm{~m}$, both gave a $\mathrm{q}$-corrected Subboreal age and showed stratigraphic concordance. The results suggest average deposition rates of 0.2 and $1 \mathrm{~cm} \mathrm{yr}^{-1}$ for the east and west locations, respectively. Deposition rates for active tufas in the area range from $0.03-1 \mathrm{~cm} \mathrm{yr}^{-1}$ (unpub data). Thorpe (1981) analyzed 22 samples of tufa from profiles in the three cascade deposits of lower Gordale (Fig 1) and obtained a mean $\delta^{13} \mathrm{C}$ of -9.82 , with $95 \%$ confidence limits -9.4 to -10.3 . There was no correlation between the $\delta^{13} \mathrm{C}$ values and ${ }^{14} \mathrm{C}$ activity in these profiles. The terrace tufas were not formed on cascades but had a virtually constant $\delta^{13} \mathrm{C}$ of -10.0 (Table 1), not significantly different $(p>0.05)$ from those of lower Gordale.

Tufa forming the active upper mound of lower Gordale (Fig 1) has a well-documented history. After a catastrophic storm ca 1730, water burst through a rock wall to form a cave-like opening known as the "Hole in the Wall" (Phillips 1853). This left the former tufa 
TABLE 1

Conventional and $q$-corrected ages $(q=0.82)$ of tufas and associated organic material. Ages for $\mathrm{q}=0.79$ are shown in parentheses. For Gordale, heights are relative to the stream level.

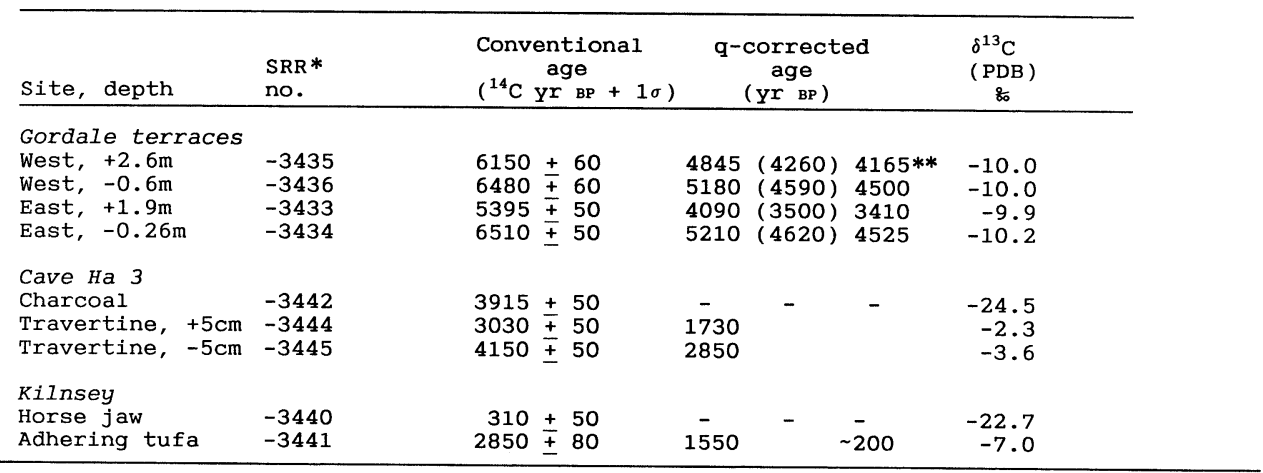

* Scottish Universities Research and Reactor Centre

$* *$ Corresponding $1 \sigma$ errors for these corrected dates are $\pm 290 \mathrm{yr}$ for $\mathrm{q}=0.85$ and $\pm 310 \mathrm{yr}$ for $\mathrm{q}=0.79$.

mound to the west dry, and the active upper mound is assumed to have begun forming after 1730 .

The bulk of the tufas composing the relict upper and lower mounds have been dated as $1910-4850$ and $4000-4500 \mathrm{BP}$, respectively. The active upper mound age was underestimated when dated with $\mathrm{q}=0.82$ but a 'correct' age was obtained when $\mathrm{q}=0.842$ (Thorpe 1981).

Pazdur and Pazdur (1986) defined the 'apparent age' of tufa associated with datable organic matter as the difference between the carbonate age and the organic age. After a statistical analysis of several ${ }^{14} \mathrm{C}$-dated profiles, Pazdur (1988) concluded that it was possible to estimate apparent age from empirical equations based on regression analysis. One equation related mean apparent age, defined as $\left\langle\mathrm{T}_{\text {app }}>\right.$, to a $\delta^{13} \mathrm{C}$ value defined as $\mathrm{a}_{\mathrm{oc}}$. The latter was obtained as the intercept of the linear regression of tufa $\delta^{13} \mathrm{C}(\mathrm{PDB})$ on carbonate age. Pazdur considered that application of this equation was acceptable for profiles where $\delta^{13} \mathrm{C}$ is not correlated to the carbonate age, organic matter is absent, and the tufa deposited in turbulent water or as carbonate mud.

The deposits of lower Gordale are classic cascade tufas formed under highly turbulent conditions. Linear regression analysis of Thorpe's (1981) measurements on a profile through this material yielded a value of $-9.56(\mathrm{~N}=11)$ for $\mathrm{a}_{\mathrm{oc}}$. Substitution of this value in Pazdur's (1988) equation 9 gave an 'apparent' age of $3.04 \pm 3.5 \mathrm{k}$ yr. Plotting our $\mathrm{a}_{\text {oc }}$ value on Pazdur's accompanying Figure 4 (p 15) gave a similar apparent age but a smaller $1 \sigma$ error of $0.6 \mathrm{k} \mathrm{yr}$. The apparent age calculated by this method is considerably higher than that obtained with q. We have not applied Pazdur's equation to our upper Gordale sites because of the small number of sampling points. We suspect that here, most of the tufa was also deposited under turbulent conditions, as it contains oncoids and the remnants of tufa barrages. However, small impoundments may also have occurred behind the barrages leading to the deposition of tufa under quiescent conditions. Some of the tufa also shows evidence of comminution and may have been transported from further upstream. Application of Pazdur's equation 9 may not be strictly valid here, but given the similar $\delta^{13} \mathrm{C}$ values to lower Gordale, the apparent age estimation would have been close to that obtained for lower Gordale.

\section{Cave Ha 3 and Kilnsey}

Cave Ha 3 is a limestone rock shelter $12 \mathrm{~km}$ west of Gordale. An excavated section revealed a $2 \mathrm{~m}$ layer of travertine below a narrow, well-defined layer of charcoal. Above the 
charcoal, another $30 \mathrm{~cm}$ of travertine occurred. Chipped stone tools and animal bones were loosely associated with the charcoal (Pentecost \& Lord 1988). The charcoal yielded a date of $3915 \pm 50 \mathrm{BP}$, consistent with the available archaeological evidence. However, the lower travertine showed age inversion when a q-correction of 0.85 was applied. Adjustment of q to give an age older than the charcoal, required values $>0.98$, suggesting negligible bedrock dilution. Another unusual feature of these travertines was their exceptionally high ${ }^{13} \mathrm{C}$ contents (Table 1). This might be explained by the admixture of limestone breccia with the deposit. The limestone $\delta^{13} \mathrm{C}$ averaged +0.63 (Thorpe 1981) and an admixture of limestone would raise $\delta^{13} \mathrm{C}$ but attenuate the ${ }^{14} \mathrm{C}$ level, giving a much older date than actually found.

If the percolating groundwater contacted the atmosphere for a period of several days prior to precipitation, almost complete equilibration with the atmospheric $\mathrm{CO}_{2}\left({ }^{13} \mathrm{C}\right.$ ca $-9 \%$ ) could occur and would raise the ${ }^{13} \mathrm{C}$ value of the travertine considerably and explain the high values observed. Complete equilibration of atmospheric $\mathrm{CO}_{2}$ with the dissolved carbonates in open karst waters where $\mathrm{HCO}_{3}^{-}$is dominant will produce a $\delta^{13} \mathrm{C}$ of $0 \pm 0.5 \%$ and a ${ }^{14} \mathrm{C}$ content equal to atmospheric levels. The equilibrium fractionation between $\mathrm{CO}_{2}$ gas and dissolved $\mathrm{HCO}_{3}^{-}$at $15^{\circ} \mathrm{C}$ ds $+9.0 \%$ (Mook 1974) giving a small ${ }^{14} \mathrm{C}$ enrichment of ca $1.8 \mathrm{pMC}$ in the dissolved bicarbonate. This indicates that the uncorrected ${ }^{14} \mathrm{C}$ age would give a better estimate of age than one corrected with $\mathrm{q}$, which emphasizes the site-specific nature of these corrections.

Near Kilnsey, $7 \mathrm{~km}$ NE of Gordale, is an active tufa-depositing site containing locally extensive tufa banks. In one of these, a horse jaw was recovered embedded in soft tufa, $75 \mathrm{~cm}$ below ground level. Collagen extracted from the jaw gave a comparatively recent date of 310 BP (Table 1) although the associated tufa yielded a much earlier q-corrected date. If tufa and jaw were coeval, the 0.85 dilution factor is clearly inappropriate, and would need to be reduced to 0.73 . Such low values have been reported elsewhere (Thorpe 1981; Srdoc et al 1982; Pazdur, Pazdur \& Szulc 1988).

The $\delta^{13} \mathrm{C}$ value for this site is higher than Gordale by ca $3 \%$. Discharge at Kilnsey is much less than at Gordale, and the feeder spring is only $200 \mathrm{~m}$ above the tufa. Deposition occurs today on a moderate slope under turbulent conditions and probably did so in the past. The dilution factor $\mathrm{q}$, for a site so close to the spring source, may well have been $<0.85$, but the $\delta^{13} \mathrm{C}$ value should then be $<-10 \%$, given the similar hydrochemistry and bedrock characters. With these uncertainties, we cannot be sure that a low q value is appropriate at this site until more measurements have been made. Application of Pazdur's (1988) equation 7 to our data gives an apparent age of $2.65 \mathrm{k}$ yr for the deposit, which would indeed suggest that bone and tufa were deposited at the same time.

\section{CONCLUSIONS}

During this investigation it soon became apparent that detailed sampling was necessary to provide sufficient information for dating purposes. Even where organic matter is present, it does not necessarily follow that the tufa and organic materials were formed at the same time. There are several sites in Craven where there is evidence of redeposition of tufa as comminuted and water-worn fragments, including upper Gordale. In such cases, organic materials are of little use for comparative dating, and could be misleading. Such situations are particularly likely where fine-grained or oncoidal material is deposited in lotic environments, eg, Gordale and Kilnsey. Pazdur, Pazdur \& Szulc (1988) obtained some evidence for redeposition in Polish tufa profiles and recognized the potential problems of dating oncoids which are particularly prone to redeposition.

Where old deposits occur in areas of active deposition, and the stable isotopic composition is age-invariant, the reliable dating of tufas, even in the absence of organic matter, should be possible. This is apparent at Gordale, where the $\delta^{13} \mathrm{C}$ levels were always close to $-10 \%$, indicating that the hydrochemical processes of limestone dissolution and tufa deposition have changed little over time.

Our studies have exposed three contrasting tufa-depositing environments and demon- 
strate that q correction factors are site-specific. Considering the great potential for variation in the $\mathrm{CO}_{2}$ sources, then bedrock dilution measurements from modern aqueous ${ }^{14} \mathrm{CO}_{2}$, corrected for bomb ${ }^{14} \mathrm{C}$, ought to give us a reasonable estimate of age in the absence of organic matter. Active sites possess clear advantages, with the potential for comparisons between modern deposits and their associated waters. It is apparent that further progress will only be made in this area using large data sets $(\mathrm{N}>10)$ taken from well-defined, preferably active sites.

\section{ACKNOWLEDGMENTS}

The Natural Environment Research Council is thanked for the use of its services, and NERC/CASE studentship GT4/77/AAPS/39. Appreciation is extended to RL Otlet and the Harwell Laboratory staff. Val Caton and Frank Carr are thanked for permission to dig up their land.

\section{REFERENCES}

Geyh, MA 1973 On the determination of the initial ${ }^{14} \mathrm{C}$ content in groundwater. In Rafter, TA and Grant-Taylor, T, eds, Intermatl radiocarbon conf, 8th, Proc. Wellington, Royal Soc New Zealand: D58-D69.

Harkness, DD and Wilson, HW 1973 Some applications in radiocarbon measurement at the Scottish Reactor Centre. In Rafter, TA and Grant-Taylor, T, eds, Internatl radiocarbon conf, 8th, Proc. Wellington, Royal Soc New Zealand:B102-B105

Mook, WG, Bommerson, JC and Staverman, WH 1974 Carbon isotope fractionation between dissolved bicarbonate and gaseous carbon dioxide. Earth Planetary Sci Letters 22:167-176.

Pazdur, A 1988 The relations between carbon isotope composition and apparent age of freshwatertufaceous sediments. Radiocarbon 30:7-18.

Pazdur, A and Pazdur, MF $1986{ }^{14} \mathrm{C}$ dating of calcareous tufa from different environments. Radiocarbon 28:534-538.

Pazdur, A, Pazdur, MF and Szulc, J 1988 Radiocarbon dating of Holocene calcareous tufa in southern Poland. Radiocarbon 30: 133-152.

Pentecost, A 1981 The tufa deposits of the Malham district, North Yorkshire. Field Stud 5:365-387.

Pentecost, A and Lord, TC 1988 Postglacial tufas and travertines from the Craven district of Yorkshire. Cave Sci 15:15-19.

Philipps, J 1853 Rivers, mountains and sea-coast of Yorkshire. London, John Murray:93p.

Srdoc, D, Horvatincic, $\mathrm{N}$ and Obelic, B 1983 Radiocarbon dating of tufa in paleoclimatic studies. In Stuiver, $\mathrm{M}$ and Kra, RS, eds, Internatl ${ }^{14} \mathrm{C}$ conf, 11 th, Proc. Radiocarbon 25(2):421-427.

Srdoc, D, Horvatincic, N, Obelic, B and Sliepcevic, A 1982 Rudjer Boskovic Institute radiocarbon measurements VII. Radiocarbon 24(3):352-371.

Srdoc, D, Obelic, B, Horvatincic, N and Sliepcevic, A 1980 Radiocarbon dating of calcareous tufa: How reliable results can we expect? In Stuiver, M and Kra, RS, eds, Internatl ${ }^{14} \mathrm{C}$ conf, 10th, Proc. Radiocarbon 22(3):858862.

Stuiver, M and Polach, HA 1977 Discussion: Reporting of ${ }^{14} \mathrm{C}$ data. Radiocarbon 19(3):355-363.

Thorpe, PM (ms) 1981 Isotope studies of UK tufa deposits and associated source waters. D Phil thesis, School Geog, Oxford Univ.

Thorpe, PM, Otlet, RL and Sweeting, MM 1980 Hydrological implications from ${ }^{14} \mathrm{C}$ profiling of UK tufa. In Stuiver, $\mathrm{M}$ and Kra, RS, eds, Internatt ${ }^{14} \mathrm{C}$ conf, 10th, Proc. Radiocarbon 22 (3):897-908.

Thorpe, PM, Holyoak, DT, Preece, RC and Willing, MJ 1981 Validity of corrected ${ }^{14} \mathrm{C}$ dates from calcareous tufa. Actes du Colloque de l'AGF. Formations carbonatees externes, tufa et travertins. Paris:151-156.

Vogel, JC 1970 Carbon-1 4 dating of groundwater. Isotope hydrology. IAEA, Vienna:225-239. 